\title{
Investigação sobre a relação entre as características do terminal de passageiros aeroportuário e as receitas não aeronáuticas
}

\author{
Rafael de Araujo Almeida ${ }^{1}$, Giovanna Miceli Ronzani Borille ${ }^{2}$ \\ ${ }^{1}$ Instituto de Controle do Espaço Aéreo - ICEA, raaralmeida@gmail.com \\ 2Instituto Tecnológico de Aeronáutica - ITA, ronzani@ita.br
}

\section{Recebido:}

26 de abril de 2017

Aceito para publicação:

16 de junho de 2017

Publicado:

30 de dezembro de 2017

Editor de área:

Anderson Ribeiro Correia

\section{Palavras-chaves:}

Aeroportos,

Terminal de Passageiros,

Receita Não Aeronáutica,

Regressão Linear.

\section{Keywords:}

Airports,

Passenger terminal,

Non-Aeronautical Revenue,

Linear regression.

DOI:10.14295/transportes.v25i4.1365

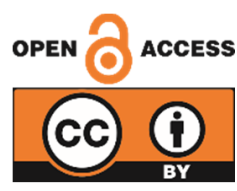

\begin{abstract}
RESUMO
Com os elevados custos associados do setor aéreo, os aeroportos enfrentam um grande desafio que é o de maximizar suas receitas. Para isso, nota-se que a ampliação das receitas provenientes de atividades não aeronáuticas aparece como uma possível solução. Nesse contexto, o objetivo deste artigo é realizar um estudo econométrico sobre as receitas não aeronáuticas dos aeroportos da rede Infraero, a fim de entender sua relevância para o operador, e quais parâmetros influenciam a captação desse re $\neg$ curso. A partir dos resultados obtidos observou-se que a participação da Receita Não Aeronáutica (RNA) sobre a Receita Total aeroportuária é de $54 \%$ e que os parâmetros mais relevantes para explicar tal receita dessa natureza são: (i) movimento de passa-geiros, (ii) área do terminal de passageiros, (iii) capacidade do estacionamento e (iv) lojas após o controle e inspeção de segurança.
\end{abstract}

\begin{abstract}
Given the high costs associated with the airline industry, airports are facing one particularly important challenge: maximize the revenue. The revenue generated from nonaeronautical activities has become increasingly interesting solution of revenue gener-ation for airports. In this context, this paper presents some preliminary findings of an econometric study aiming at estimating the impacts of non-aeronautical revenues. Ac-cording to the results, non-aeronautical revenue accounted for 54 percent compared with total operating revenue. Passenger movement, passenger terminal area, car park-ing capacity and retail/duty-free (located in the departures area of the terminal, after security control) are of the most important factors that affect the non-aeronautical
\end{abstract} revenue.

\section{INTRODUÇÃO}

Observa-se que os operadores dos aeroportos estão indo além do que meros prestadores de serviços aeronáuticos no século 21 . Os seus atuais modelos de receita aeroportuária têm se tornado altamente diversificados e sofisticados. 0 tipo de receita que tem se destacado nesse novo padrão financeiro de aeroportos é a Receita Não Aeronáutica, que surge como opção adicional para momentos críticos na economia (ACI, 2015). A classificação de Receita Não Aeronáutica abrange quaisquer receitas que envolvem acordos comerciais que o aeroporto faz em relação à outorga de concessões, aluguel ou leasing de instalações e/ou áreas foras da zona de operação aeronáutica, embora os acordos também possam envolver atividades consideradas de caráter aeronáutico como, por exemplo, aluguel de terminais ou instalações para operadores de aeronaves (ICAO, 2013).

A fim de entender o cenário econômico atual dos aeroportos mundiais vale acompanhar a evolução 
da atividade aeroportuária ao longo dos anos. Na década de 1970, o projeto relacionado com a infraestrutura dos aeroportos era focado no processamento de passageiros e aeronaves, e esse tipo de operação limitava as possibilidades de captação de diferentes tipos de receitas que não fossem as aeronáuticas. Ao final da década de 70, em 1978, houve o Ato de Desregulação nos Estados Unidos, evento esse que desencadeou uma mudança significante na forma de gestão dos aeroportos. Diante deste cenário, em 1990, o objetivo do operador aeroportuário passou a ser o aumento da receita e da lucratividade, por isso a Receita Não Aeronáutica começou a ganhar destaque.

Atualmente, a gestão aeroportuária vê-se diante de um cenário desafiador, que é a redução da dependência financeira da operação aeronáutica. Esse novo modelo busca um portfólio de fonte de receita mais abrangente e de menor risco. Tal conceito pode ser observado através da diversidade de atividades e serviços oferecidos em muitos aeroportos como lojas, escritórios, hotéis, áreas de lazer, centros de convenção entre outros. No entanto, o panorama mundial em relação à margem de lucro dos aeroportos apresenta algumas questões que merecem atenção. Como pode ser observado na Figura 1, os aeroportos mundiais com menos de 1 milhão de passageiros anual possuem margem de lucro negativa de -11,9\% na média, e quanto maior o aeroporto, em termos de movimento de passageiros, a margem de lucro é positiva e aumenta na média, existindo apenas uma descontinuidade para a faixa de 25 a 40 milhões de passageiros. Nota-se ainda que a lucratividade de forma global é positiva, embora muitos representantes ainda são deficitários, principalmente, aqueles cujo o tráfego de passageiros não supera a movimentação de 1 milhão por ano.

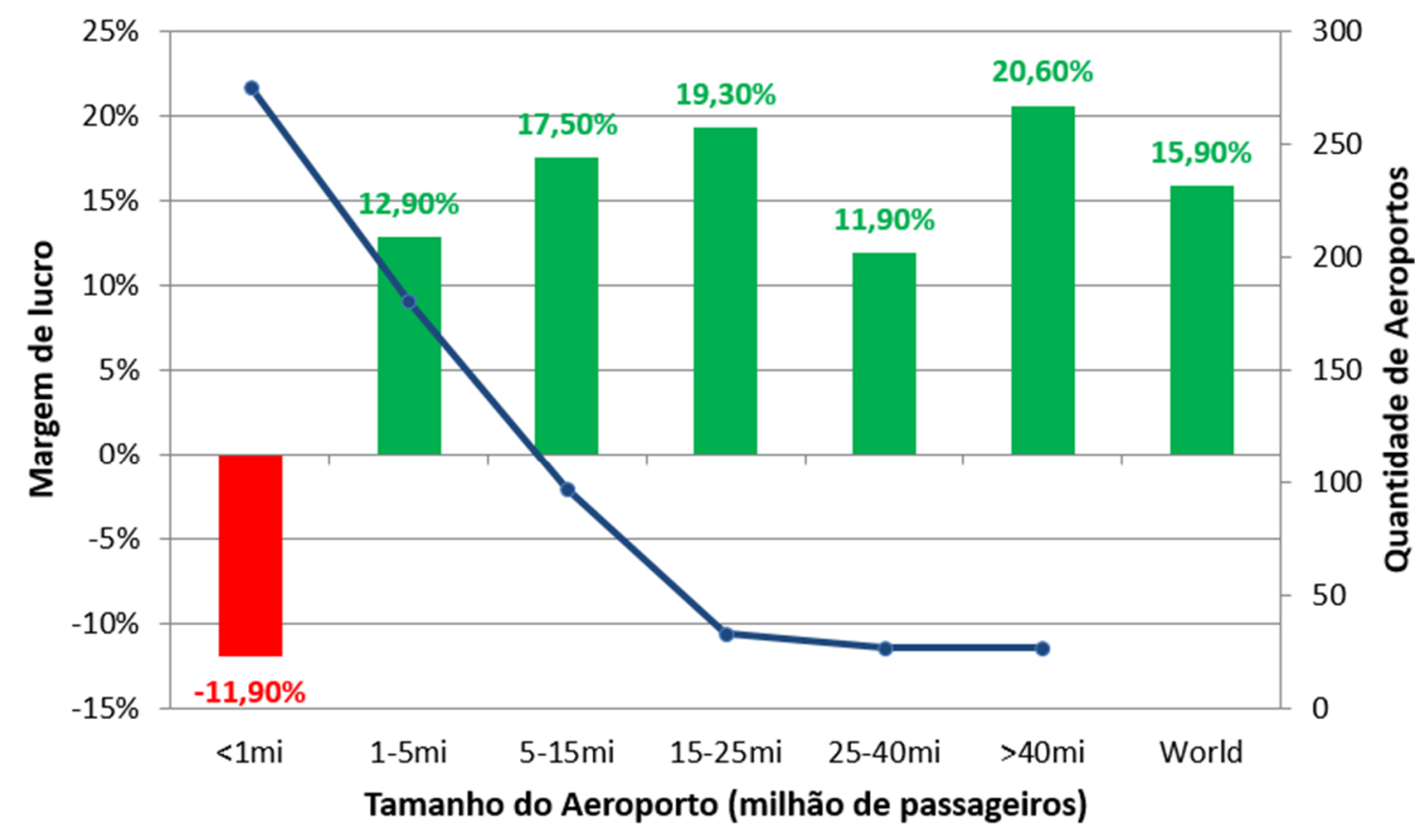

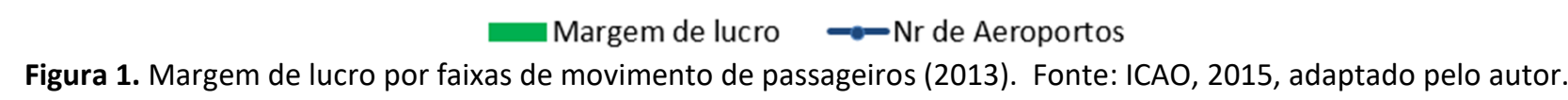

No contexto nacional, a Infraero, que até o ano corrente, é a responsável por administrar a maior rede de aeroportos brasileiros, apresenta um cenário crítico em relação à sua rentabilidade. 0 quadro financeiro da empresa apresentou déficit pelo $3^{\circ}$ ano consecutivo, sendo que em 2015 atingiu o déficit de 3 bilhões de reais (Gazeta do Povo, 2016). Uma solução para minimizar o problema da lucratividade negativa ou até mesmo torná-la rentável é o investimento e as adequações da infraestrutura aeroportuária com objetivo de aumentar a Receita Não Aeronáutica. Além disso, é também a estratégia para as grandes empresas administradoras de aeroporto para maximizar os lucros, podendo superar os $70 \%$ de participação da Receita Não Aeronáutica sobre a receita total. 
Diante deste cenário, este trabalho propõe realizar um estudo econométrico sobre as Receitas Não Aeronáuticas dos aeroportos da rede Infraero a fim de entender a importância dessa receita para o operador, e ainda, identificar quais os fatores influenciam a captação desse recurso. Vale ressaltar que, o estudo abrange apenas os valores relativos aos aeroportos e não aos centros administrativos e EPTAs (Estação Prestadora de Serviço de Telecomunicações e de Tráfego Aéreo). 0 estudo busca investigar (i) a importância da Receita Não Aeronáutica para a rede Infraero, (ii) quanto é o incremento da Receita Não Aeronáutica para cada passageiro, (iii) os aspectos da infraestrutura do terminal de passageiros que impactam nas Receitas Comerciais, e ainda (iv) aspectos de marketing no terminal de passageiros que são essenciais para o perfil dos aeroportos da rede Infraero. Para atender aos objetivos propostos, o presente trabalho é particionado como explicitado a seguir. Na primeira parte deste artigo são introduzidos os conceitos das classificações das receitas aeroportuárias. Na segunda parte são apresentados os principais trabalhos desenvolvidos na área de estudo, sendo base para o desenvolvimento deste artigo. Na terceira seção é exposta a metodologia do estudo. Em seguida, na quarta parte, são apresentados as análises e o resultado do modelo econométrico. Por último é feita a conclusão do estudo, destacando os principais resultados e as limitações do trabalho.

\section{CONCEITOS}

As principais classificações das receitas aeroportuárias são abordadas por Jenichen (2002), conforme pode ser visto na Tabela 1, que está em concordância com diversos autores, inclusive com a ICAO - International Civil AviationOrganization (ICAO, 2013).

Tabela 1: Quadro resumo das Receitas Aeroportuárias. Fonte: Jenichen, (2002).

\begin{tabular}{|c|c|c|c|}
\hline \multirow{3}{*}{$\begin{array}{c}\text { Receitas } \\
\text { Aeroportuárias }\end{array}$} & \multirow[t]{2}{*}{$\begin{array}{c}\text { Receitas } \\
\text { Operacionais }\end{array}$} & $\begin{array}{c}\text { Receitas } \\
\text { Aeronáuticas }\end{array}$ & $\begin{array}{c}\text { Tarifas de Pouso } \\
\text { Tarifas de Excesso de Load-Factor } \\
\text { Tarifas de Segurança } \\
\text { Tarifas de Embarque } \\
\text { Tarifas de Permanência no Pátio de Manobras }\end{array}$ \\
\hline & & $\begin{array}{l}\text { Receitas Não } \\
\text { Aeronáuticas }\end{array}$ & $\begin{array}{l}\text { Locações e Arrendamentos para Empresas Aéreas } \\
\text { Locações e Arrendamentos para outras Concessionárias }\end{array}$ \\
\hline & $\begin{array}{l}\text { Receitas Não } \\
\text { Operacionais }\end{array}$ & & $\begin{array}{l}\text { Investimentos } \\
\text { Operações de Crédito } \\
\text { Venda de Serviços }\end{array}$ \\
\hline
\end{tabular}

Primeiramente, as receitas se dividem em função da operação, sendo operacional ou não operacional. As receitas não operacionais são derivadas de atividades que não estão relacionadas ao movimento de aeronaves, passageiros e carga, como, por exemplo, investimentos, consultorias entre outros. As receitas operacionais são aquelas geradas devido à operação do aeroporto, ou seja, relacionadas ao movimento de aeronaves, de passageiros e de carga. Por sua vez, as receitas operacionais podem ser subdivididas em aeronáuticas e não aeronáuticas, em que estas são geradas das atividades comerciais não relacionadas com as operações de voo, podendo ser através da exploração das áreas e das instalações do aeroporto, enquanto aquelas são geradas de atividades de pouso e decolagem de aeronaves, e também o processamento de passageiros e cargas. 0 relatório econômico da ACI - Airports Council International (2015) fornece a média da distribuição das receitas a nível global, como segue: não operacional (4,1\%), não aeronáutica $(40,4 \%)$ e aeronáutica $(55,5 \%)$.

A classificação das receitas apresentada pela Infraero apresenta uma nomenclatura diferenciada, no entanto, com conceitos equivalentes (ANAC, 2014). A divisão das receitas pela Infraero é: (i) Armazenagem e Capatazia; (ii) Atividades Não Reguladas; (iii) Embarque Doméstico; (iv) Embarque Internacional; (v) Operação de Pouso Doméstico; e (vi) Operação de Pouso Internacional. Segundo a definição extraída do relatório Financeiro da Infraero (ANAC, 2014), as receitas das atividades não reguladas são aquelas provenientes de atividades para as quais não há regulação tarifária e que, portanto, geram receitas al- 
ternativas, tais como aquelas decorrentes da concessão de áreas para exploração comercial, ganhos financeiros, prestação de demais serviços não regulados, entre outros.

A Figura 2 mostra a relação entre os conceitos de ambas as organizações. Sendo assim, as receitas de embarque e pouso, doméstico e internacional, enquadram-se nas receitas aeronáuticas, enquanto que as receitas de armazenagem, capatazia e atividades não reguladas relacionam-se as receitas não aeronáuticas e não operacionais.

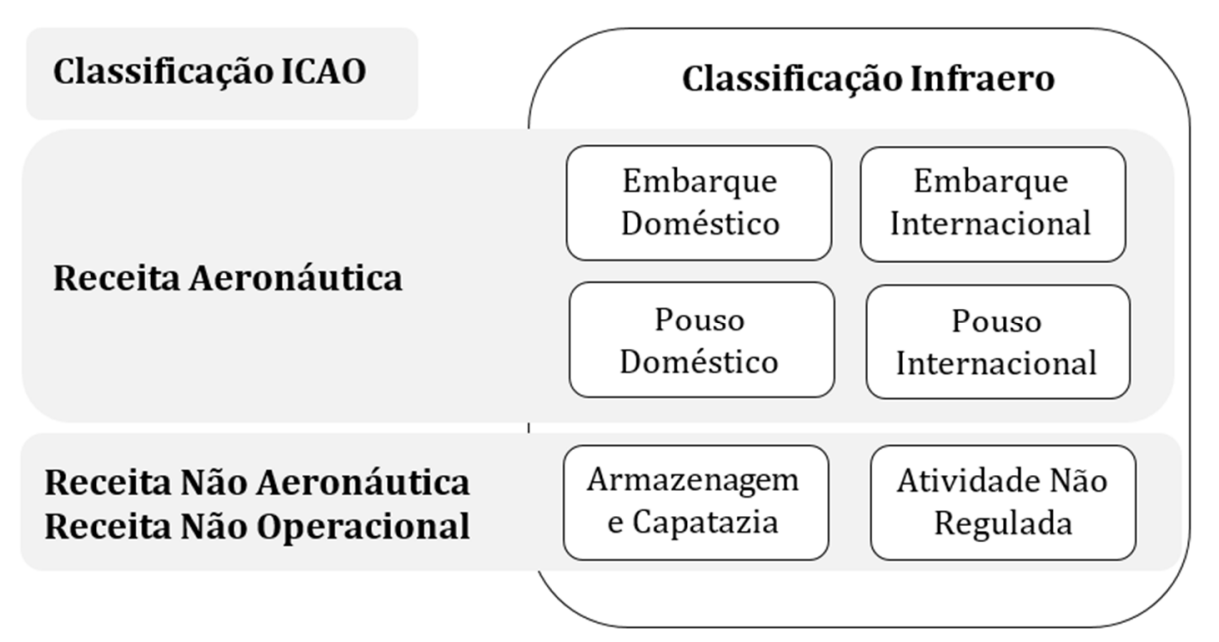

Figura 2. (Relação entre classificação de Receita: ICAO (ICAO, 2013) e Infraero (ANAC, 2014).

Dada a importância da Receita Não Aeronáutica para a operação, a manutenção e o desenvolvimento de um aeroporto, é reforçada a relevância de um adequado planejamento e projeto de um terminal de passageiros no que diz respeito à designação de áreas de concessão (áreas para fins comerciais). Segundo a IATA (2014), tipicamente, os planejadores tentam dedicar em torno de $15 \%$ da área do terminal de passageiros para varejo, alimentação e comércio, entre outros. De qualquer forma, vale ressaltar que não existe um consenso quanto à quantidade ideal de espaço, afinal cada aeroporto deve ser projetado e operado conforme suas particularidades. Além disso, como afirma Graham (2008) é importante identificar o perfil dos usuários do aeroporto (passageiros embarcando, passageiros desembarcando, passageiros em conexão, passageiros viajando à lazer, passageiros viajando à negócios, visitantes, funcionários, etc). De posse destas informações, os planejadores e operadores aeroportuários podem definir de forma mais adequada quais as atividades comerciais são mais atraentes para serem ofertadas.

Ao analisar a literatura, nacional e internacional, que abordam o assunto sobre áreas de concessão em interiores de aeroportos, encontram-se algumas pesquisas como as mencionadas na sequência.

No que diz respeito ao passageiro (cliente-chave do aeroporto), Emberson (2007) destaca que o comportamento ou a pré-disposição às compras pode diferenciar entre as áreas públicas e áreas restritas do terminal de passageiros. Quando o passageiro chega ao aeroporto de origem (no lado terra ou na área pública do terminal de passageiros), inicialmente, existe a preocupação em realizar o check-in, despachar bagagens e identificar o local de acesso à sala de embarque. Somente após a concretização desses procedimentos é que o passageiro sente-se mais relaxado e em condições de decidir o que fazer durante o tempo de espera até o seu embarque. Desta forma, acredita-se que após os procedimentos de Inspeção de Segurança e Controle de Passaporte, ou seja, na área de acesso restrito do terminal de passageiros (lado ar), é essencial dedicar área suficiente para varejo, alimentação, serviços, entre outros. Segundo a ACRP 25 (2010) fornecer espaço adicional para estas atividades comerciais em um aeroporto, as quais são altamente geradoras de rendimento, pode ser muito benéfico para a questão financeira de um aeroporto.

Torres et al (2005) mencionam que existe uma evidente relação entre os gastos do passageiro nas áreas comerciais do aeroporto e o tempo que o passageiro permanece no terminal até o momento do 
embarque na aeronave. Além disso, afirmam que os passageiros à lazer tendem a comprar mais no aeroporto ao comparar com passageiros viajando à negócios. Ao investigar a importância das receitas comerciais para os aeroportos, Graham (2009) menciona que o varejo é uma das fontes mais significativas. Além disso, também destaca que as atividades comerciais localizadas no lado ar do aeroporto tendem a ser mais rentáveis, pois é local onde os passageiros estão mais propensos para comprar e/ou consumir. Castillo-Manzano (2010) analisa os fatores que influenciam na decisão dos passageiros de (i) comprar e/ou (ii) consumir em lojas de aeroportos espanhóis e, para ambas as situações foi detectado que o tempo de espera antes de embarcar é uma importante variável que influencia na decisão de compra/consumo do passageiro. Del Chiappa et al (2016) citam sobre a escassez de literatura acadêmica sobre o assunto e reforçam que grande parte lucratividade de aeroportos tem como base as receitas não-aeronáuticas, especialmente, advindas das atividades comerciais. Os referidos autores analisam a qualidade dos serviços de varejo (especialmente relacionados com bebida e comida) sob a percepção do passageiro. No total, foram entrevistados 551 passageiros no Aeroporto Olbia Costa Smeralda/Itália e identificados como pontos de melhoria, para o aeroporto estudo de caso, correções nos quesitos " preços mais acessíveis" e " provisão de entretenimento".

Quanto aos métodos de análise, observa-se uma vasta literatura utilizando estudos econométricos para análise de precificação e receita de companhias aéreas, mas bem menos estudos desse tipo quando se trata de receitas e tarifas aeroportuárias (Dender, 2006). Por isso, nesta seção também são apresentados alguns desses trabalhos que forneceram subsídios para este estudo.

Jenichen (2002) apresenta a descrição dos tipos de receitas e despesas aeroportuárias, realizando então uma análise econométrica desses dados para o caso dos aeroportos administrados pela DAESP Departamento Aeroviário do Estado de São Paulo. Entre seus modelos é observado que o movimento de passageiros é a variável explicativa para a receita comercial. Tovar e Martin-Cejas (2009) realizaram um estudo por análise de envoltória de dados, com aeroportos da Espanha, concluindo que a proporção de passageiros internacionais que circulam no terminal de passageiros impacta positivamente a receita comercial e que aeroportos que possuem atividades comerciais mais desenvolvidas são mais eficientes do que aqueles com foco na receita aeronáutica. Volkova (2009) abordou 13 aeroportos europeus em um estudo econométrico, chegando em algumas conclusões tais como: (i) mais passageiros da União Européia aumentam a receita de lojas por metro quadrado em aeroportos tipo hub; (ii) a quantidade de vagas de estacionamento disponível para pequeno tempo de parada, facilidades no check-in e número de empregados contribuem para a receita de varejo; (iii) lojas de alimentação (bar e restaurante) influenciam a receita de varejo e geram externalidades; (iv) mais passageiros da União Europeia não tem efeito sobre a receita de varejo em aeroportos regionais. Fuerst e Gross (2014), também realizando estudos econométricos por meio de análise de regressões, investigaram 75 aeroportos no mundo, resultando que quanto maior a porcentagem de lojas de alimentação, menor será a receita comercial, e também que quanto maior a porcentagem de lojas localizadas após o controle de segurança, maior será a receita comercial.

De uma forma geral, observa-se na literatura que o tema ainda é pouco explorado e existe o consenso de sua grande importância, afinal as receitas das atividades não aeronáuticas mostram-se como lucrativas e essenciais para a saúde financeira de um aeroporto. Sendo assim, o presente artigo pretende abordar o assunto, com especial enfoque em aeroportos brasileiros.

\section{METODOLOGIA}

A sistemática utilizada neste estudo segue a característica de modelos econométricos utilizando regressão linear múltipla, no entanto, para explicitar cada etapa do desenvolvimento da pesquisa e apontar as principais considerações é apresentado o fluxograma na Figura 3. 


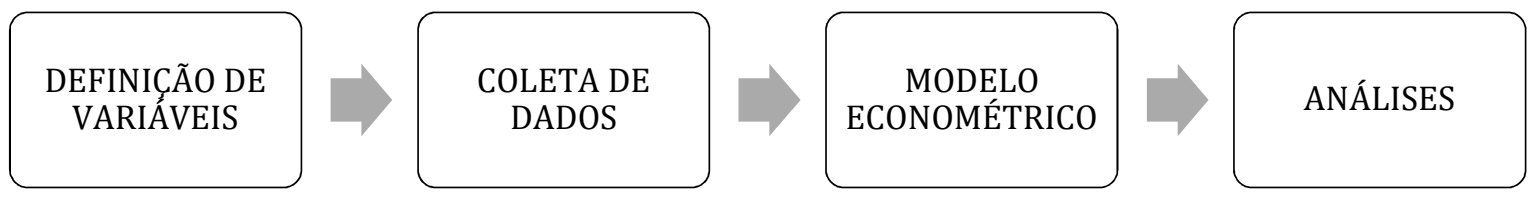

Figura 3: Fluxograma das etapas da pesquisa

A fase inicial de definição de variáveis é necessária para elencar as variáveis de interesse, conforme objetivo do artigo, buscando suporte na literatura ou relatórios para se considerar tal parâmetro. Na sequência tem-se a coleta de dados, que é a etapa onde será realizado o levantamento das informações das variáveis determinadas na fase anterior. Nessa etapa ocorrem algumas limitações devido à dificuldade de obtenção de dados. Sendo assim, a abrangência dos dados obtidos conta com informações do ano de 2015 de 60 aeroportos da rede de aeroportos Infraero, os quais não consideram, para o ano de confecção deste artigo (2016), os aeroportos em concessão (5 aeroportos sob concessão em 2015) e que são os de maior movimento de passageiros.

A Tabela 2 apresenta as variáveis utilizadas neste presente trabalho, sua descrição, a fonte do dado, a principal referência base para origem da possibilidade de se considerar a variável e o número de observações. É possível observar que algumas variáveis não atingiram o valor amostral de 60, isso ocorreu devido, principalmente, a dificuldade de obtenção de dados. Devido à indisponibilidade do dado desagregado de receita não operacional da receita de atividade não regulada, foi considerado que a Receita Não Aeronáutica é igual a receita de armazenagem e capatazia, e de atividade não regulada.

Tabela 2: Descrição das variáveis

\begin{tabular}{|c|c|c|c|c|}
\hline $\begin{array}{l}\text { Variá- } \\
\text { vel }\end{array}$ & Descrição & Fonte & Referência & Obs. \\
\hline RNA & Receita Não Aeronáutica (R\$) & Infraero & (Jenichen, 2002) & 60 \\
\hline RANR & $\begin{array}{c}\text { Receita de Atividade Não Regulada (R\$) somente para } \\
\text { Aeroporto com voo regular }\end{array}$ & Infraero & $\begin{array}{l}\text { (Fuerst \& Gross, } \\
\text { 2014) }\end{array}$ & 53 \\
\hline MOV & Movimento de Passageiros Anual & (Infraero, 2016) & (Jenichen, 2002) & 60 \\
\hline CARG & Quantidade de carga anual (Toneladas) & (Infraero, 2016) & (Jenichen, 2002) & 60 \\
\hline ATPS & Área total do terminal de passageiros $\left(\mathrm{m}^{2}\right)$ & (Infraero, 2016b) & $\begin{array}{l}\text { (Fuerst \& Gross, } \\
\text { 2014) }\end{array}$ & 60 \\
\hline LOJ & Quantidade total de lojas e serviços oferecidos & (Infraero, 2016a) & (ICAO, 2015) & 60 \\
\hline SVC & Quantidade de serviços oferecidos & (Infraero, 2016a) & (ICAO, 2015) & 60 \\
\hline$F \& B$ & Quantidade de lojas de alimentação (restaurantes e bar) & (Infraero, 2016a) & (ICAO, 2015) & 60 \\
\hline SHOP & Quantidade de lojas de varejo & (Infraero, 2016a) & (ICAO, 2015) & 60 \\
\hline CAR & Quantidade de locadoras de carro & (Infraero, 2016a) & (ICAO, 2015) & 60 \\
\hline LCS & $\begin{array}{c}\text { Quantidade total de lojas e serviços após o controle de } \\
\text { segurança }\end{array}$ & (Infraero, 2016b) & $\begin{array}{l}\text { (Fuerst \& Gross, } \\
\text { 2014) }\end{array}$ & 48 \\
\hline EST & Capacidade do estacionamento & (Infraero, 2016b) & (ICAO, 2015) & 60 \\
\hline ESTP & Dummy ${ }^{(\mathrm{a})}:$ Estacionamento pago? & (Google Maps, 2016) & (ICAO, 2015) & 60 \\
\hline ESTC & Dummy: Estacionamento sob concessão? & (Infraero, 2016a) & (ICAO, 2015) & 60 \\
\hline DTUR & Dummy: local turístico? & $\begin{array}{l}\text { (Ministério do Turismo, } \\
\text { 2012) }\end{array}$ & - & 60 \\
\hline DCOM & $\begin{array}{c}\text { Dummy: Existe comércio próximo do acesso ao terminal } \\
\text { de passageiros? }\end{array}$ & (Google Maps, 2016) & - & 60 \\
\hline MINT & Dummy: Marca de loja internacional? & (Infraero, 2016b) & (DKMA, 2014) & 54 \\
\hline MLOC & Dummy: Marca de loja local/regional? & (Infraero, 2016b) & (DKMA, 2014) & 53 \\
\hline DOL & $\begin{array}{l}\text { Dummy: Existe opções de lojas? } \\
\text { (pelo menos } 2 \text { de cada setor) }\end{array}$ & Derivado & (DKMA, 2014) & 60 \\
\hline
\end{tabular}

(a)Dummy: Variável booleana, que assume os valores 0 ou 1 para indicar a ausência ou presença de algum efeito.

A terceira etapa conta com o modelo econométrico, utilizando a regressão múltipla linear. A equação (1) é a expressão geral e a equação (2) expressa o formato matricial linear aberto.

$$
Y=X \beta+\varepsilon
$$


m que Y: Matriz de variáveis a serem explicadas;

X: Matriz de variáveis explicativas;

$\beta$ : Matriz de parâmetros a serem estimados; e

$\varepsilon$ : vetor de resíduos.

$$
\left[\begin{array}{c}
Y_{1} \\
Y_{2} \\
\vdots \\
Y_{n}
\end{array}\right]=\left[\begin{array}{cccc}
1 & X_{11} & \ldots & X_{1 k} \\
1 & X_{21} & \ldots & X_{2 k} \\
\vdots & \vdots & \ddots & \vdots \\
1 & X_{n 1} & \ldots & X_{n k}
\end{array}\right] \cdot\left[\begin{array}{c}
\beta_{1} \\
\beta_{2} \\
\vdots \\
\beta_{n}
\end{array}\right]+\left[\begin{array}{c}
\varepsilon_{1} \\
\varepsilon_{2} \\
\vdots \\
\varepsilon_{n}
\end{array}\right]
$$

O software utilizado para auxiliar o processamento das equações e análises estatísticas foi o Stata versão MP 14.1. Esse é muito utilizado em tarefas de Econometria, utilizando dados cross-section, dados em painel e estimação de séries temporais. Por fim, tem-se a fase de análises dos outputs e avaliação dos parâmetros estimados. Vale ressaltar que durante os testes do modelo e análises pode-se verificar ainda a necessidade de inserção de novas variáveis, retornando assim para a primeira fase de definição de variável e a sequência do fluxograma.

\section{ANÁLISES E RESULTADOS}

Com a finalidade de entender o comportamento dos aeroportos da rede Infraero é importante destacar o panorama global da referida rede. Assim como analisado no contexto mundial, o gráfico da Figura 4 apresenta a margem de lucro da rede Infraero por tamanho do aeroporto em termos do movimento de passageiros no ano de 2015.

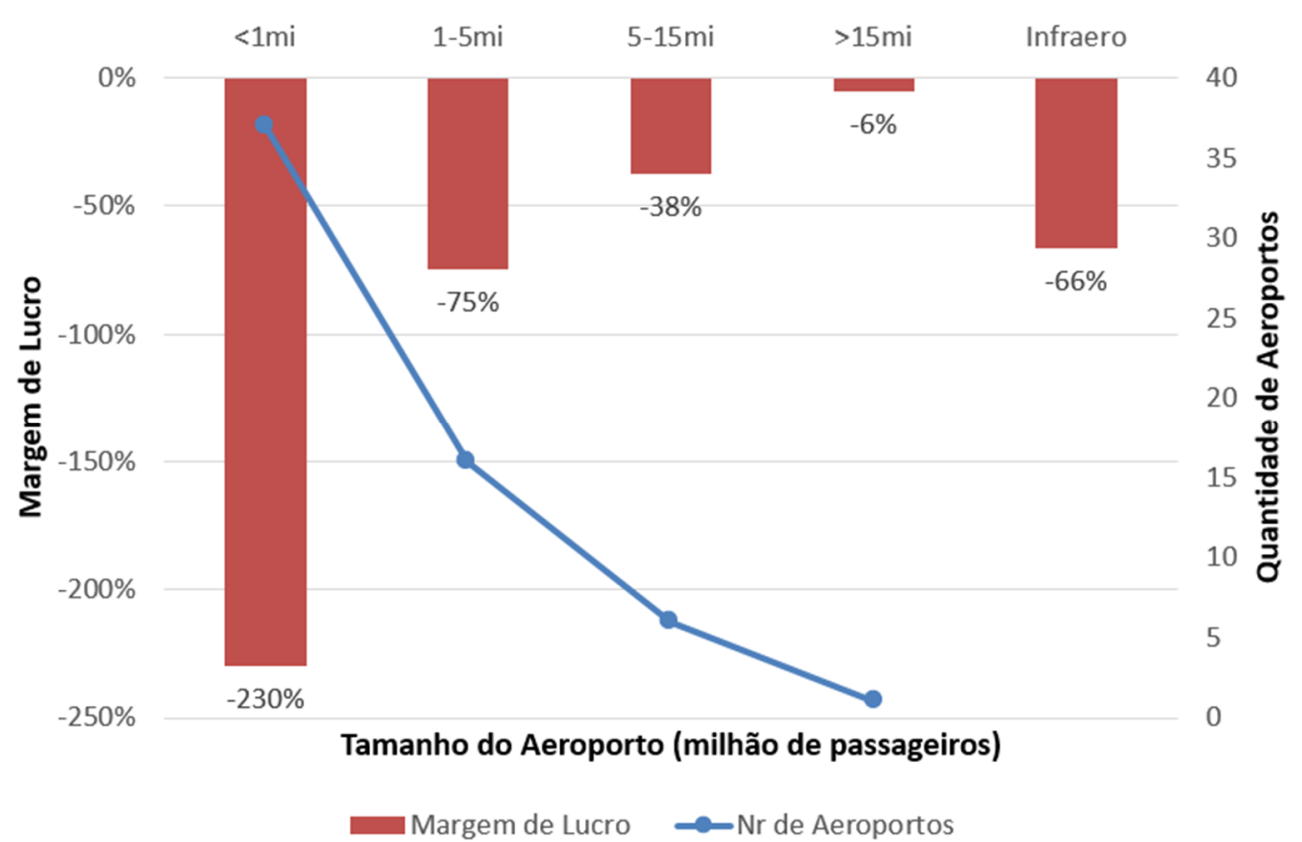

Figura 4. Margem de lucro por faixa de movimento de passageiros para o ano de 2015: aeroportos da rede Infraero.

Como pode-se observar na Figura 4, de maneira geral, os aeroportos da Infraero têm apresentado prejuízo financeiro em todos os níveis de aeroportos, independente da quantidade de movimento de passageiros. Isso não significa que alguns casos possam ter lucro positivo, mas sim que a média da margem de lucro está negativa. Sendo assim verifica-se que a média da margem de lucro global da Infraero está em -66\%. Nota-se ainda que aeroportos com menos de 1 milhão de passageiros anual, que são a maioria dos aeroportos da rede, possuem margem de lucro negativa de $-230 \%$ na média. E quanto maior 
o aeroporto, em termos de movimento de passageiros, a margem de lucro aumenta, embora ainda permaneça negativada.

Analisando a razão entre a Receita Não Aeronáutica (RNA) e a Receita Total aeroportuária obtém-se uma média de $54 \%$. Na Figura 5 é possível observar a frequência dessa mesma relação para todos os aeroportos da rede, dessa forma a maior ocorrência está entre a faixa de 30\% a 60\%.

A primeira variável a ser explicada é a Receita Não Aeronáutica (RNA), em que as variáveis explicativas testadas foram movimento de passageiros anual (MOV), quantidade de tonelada de carga anual (CARG), quantidade de passageiros internacionais (PAXI), área total do terminal de passageiros (ATPS) e por fim a variável dummy para local turístico (DTUR).

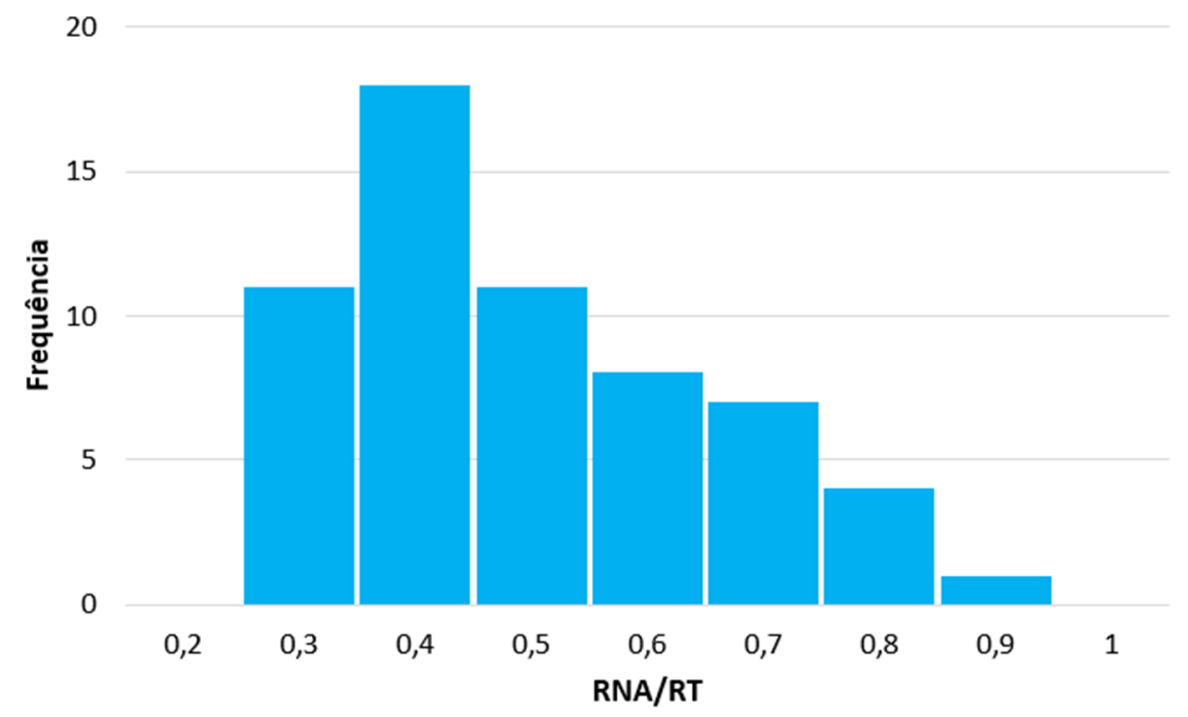

Figura 5. Histograma da participação da RNA na Receita Total (RT).

A Tabela 3 apresenta os resultados das regressões para a RNA, em que foram estimadas 3 equações. Inicialmente, no modelo 1, percebe-se que há significância estatísticas dos fatores movimentos de passageiros, carga e passageiros internacionais, todas com elasticidade positiva em relação à RNA, ou seja, quanto maiores os fatores maior a Receita Não Aeronáutica.

Tabela 3: Resultados das regressões para a RNA

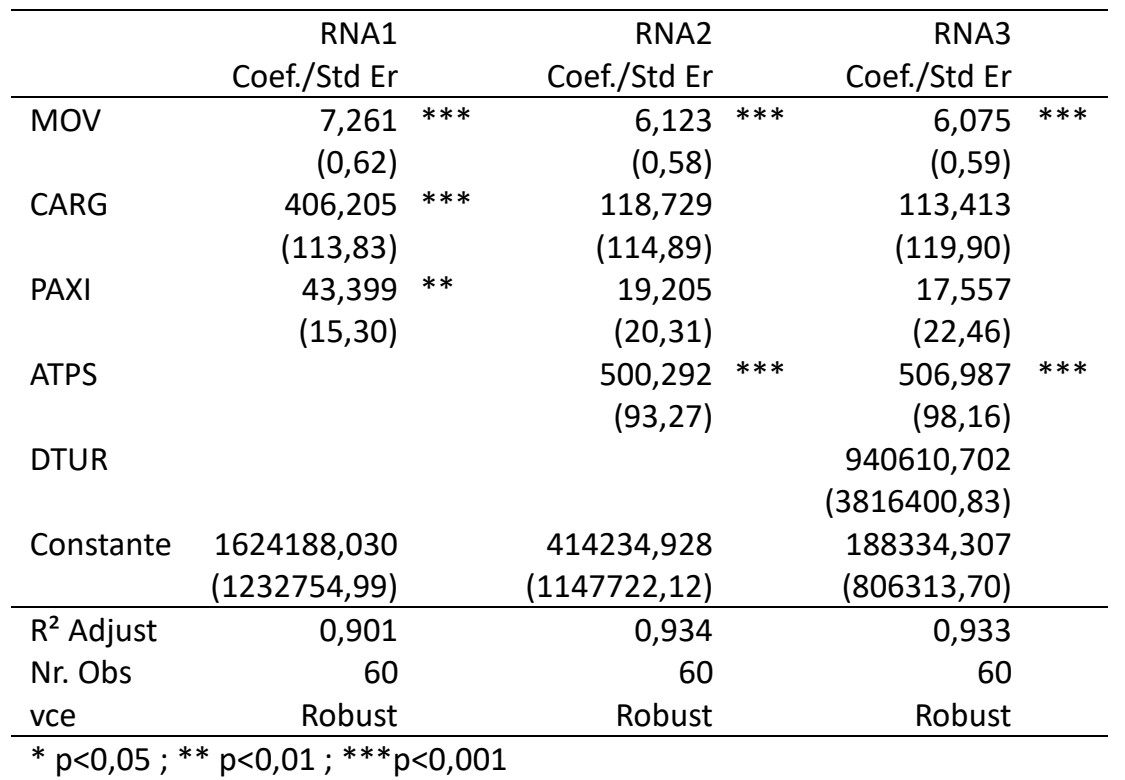


Para os modelos 2 e 3 foram inclusos as variáveis área do terminal de passageiros e dummy de local turístico, respectivamente. Nesses casos os fatores carga e passageiro internacional não foram significativos, massim o movimento de passageiros e a área do terminal. Como o modelo 3, que apresenta a dummy de local turístico, não alterou a quantidade de variáveis explicativas significativas e reduziu o $\mathrm{R}^{2}$ ajustado mantém-se a regressão do modelo 2 como melhor ajuste. Logo, a elasticidade do movimento é de 6,1 e da área do terminal de passageiros é de 500,3.

No modelo 2, verificou-se que, além das duas variáveis anteriores que apresentaram relevância estatística (LCS e EST), a variável de lojas de alimentação (F\&B) também é explicativa com nível de significância menor, $\mathrm{R}^{2}$ ajustado de 0,881 e elasticidade negativa, ou seja, mais lojas de alimentação reduzem a receita de atividade não regulada. Esse efeito pode ser função do potencial de arrecadação das demais lojas como, por exemplo, locadora de carro e varejo.

Tabela 4: Resultados das regressões para a RANR

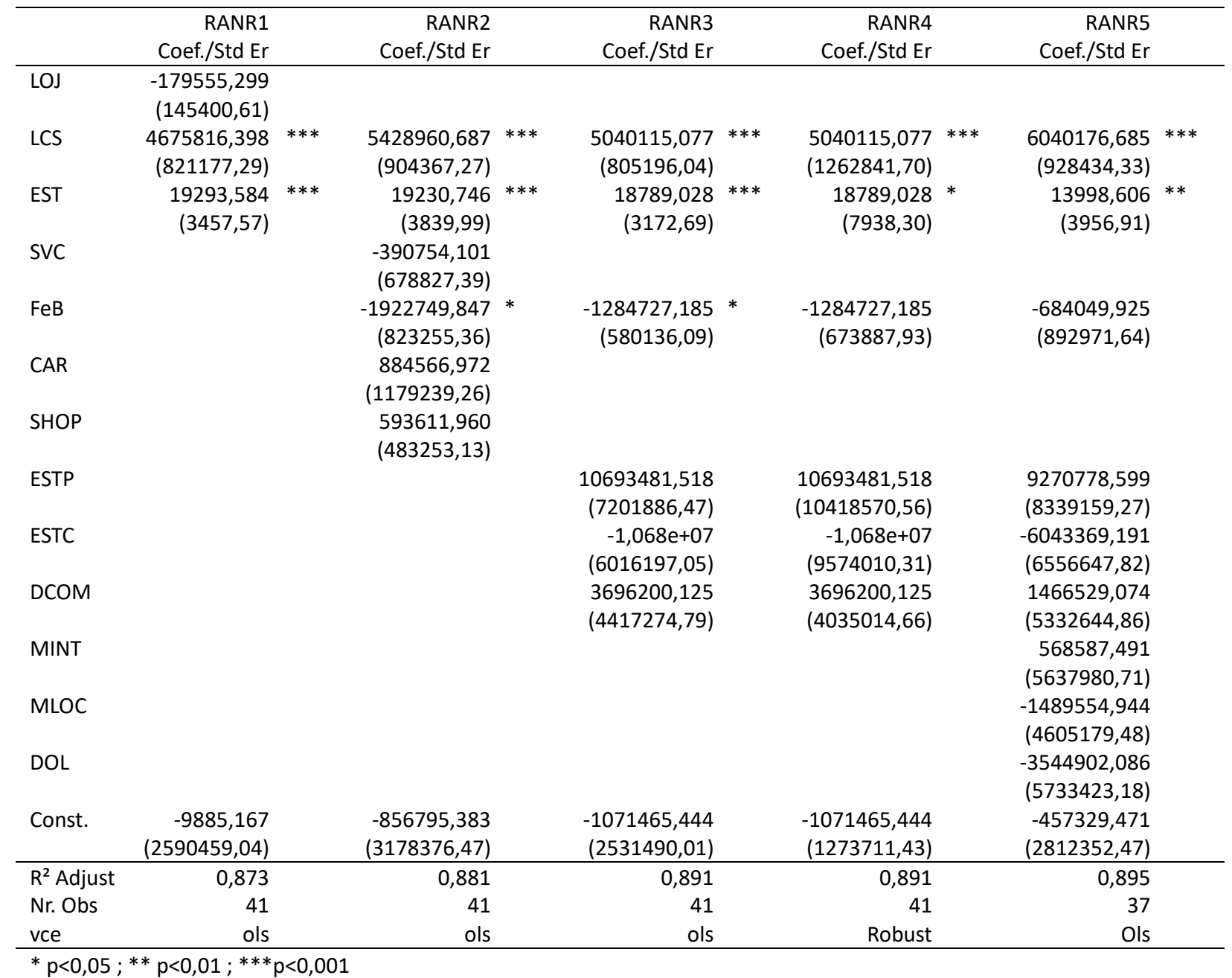

0 modelo 5, adicionou variáveis para identificar alguma influência devido às estratégias de percepção de alternativas de lojas e serviços pelo passageiro, mas nenhuma delas se mostrou consistente ao nível de significância menor do que $5 \%$. Como o $\mathrm{R}^{2}$ ajustado foi elevado apenas para 0,895 frente ao acréscimo de diversas variáveis, optou-se por um modelo explicativo sem a interferência de tantas variáveis com a probabilidade de nulidade acima do esperado.

0 modelo 3 e 4 apresentam os mesmos tipos de variáveis, com a diferença de que o modelo 4 apresenta regressão linear mais criteriosa utilizando o modelo de robustez para o controle de heteroscedasticidade, que apresenta a forte dispersão dos dados perante um modelo econométrico regredido. Oerro padrão foi diferente e também diminuiu a significância estatística das variáveis. 
Analisando o modelo 4, percebe-se que: seu $\mathrm{R}^{2}$ ajustado é 0,891 , que demonstra o nível de ajuste da reta estimada à amostra; e as variáveis LCS e EST são as que explicam melhor a receita de atividade não regulada, com elasticidades de 5.040.115 e 18.789, respectivamente. Embora outras variáveis do modelo 4 não sejam estatisticamente significantes, vale notar as tendências de sinal para um possível estudo mais detalhado. Verificando assim que as variáveis lojas de alimentação e estacionamento sob concessão reduzem o potencial de receita, enquanto estacionamento pago e proximidade com comércio aumentam a possibilidade de receita.

\section{CONCLUSÕES}

Este artigo propôs-se realizar um estudo sobre as receitas não aeronáuticas dos aeroportos da rede Infraero a fim de entender a importância dessa receita para o operador, e quais fatores influenciam a captação desse recurso. Para isso, utilizou-se modelos econométricos de regressão linear múltipla por meio da ferramenta Stata para análise de uma base de dados - elaborada pelos autores - com diversas fontes de entrada, principalmente, com dados obtidos da própria Infraero. Verificou-se que os aeroportos da rede Infraero têm apresentado prejuízo financeiro em todos os níveis de aeroportos, apresentando uma média da margem de lucro global de -66\%. Destaca-se o atual perfil de seus aeroportos, que não ultrapassam o movimento de 1 milhão de passageiros anual. Sabendo que quanto maior o aeroporto, em termos de movimento de passageiros, a margem de lucro aumenta, o caráter deficitário da Infraero é potencializado, dado que os 5 aeroportos mais movimentados estão sob contratos de concessão, considerando o ano de 2016 (quando o presente artigo foi elaborado). A participação da Receita Não Aeronáutica (RNA) sobre a Receita Total aeroportuária é de 54\%, ou seja, é um percentual significativo que merece atenção do operador e ainda existe margem para aumento dessa natureza de receita. Foi identificado que os parâmetros mais relevantes para explicar a Receita Não Aeronáutica são movimento de passageiros e área do terminal de passageiros com elasticidades 6,1 e 500,3, respectivamente. Enquanto que os principais fatores para a receita de atividade não regulada foram a capacidade do estacionamento e lojas após o controle de segurança, com elasticidade de 18.800 e 5.040.100, respectivamente. As limitações desse estudo consistiram na indisponibilidade do dado desagregado de receita não operacional da receita de atividade não regulada, além da limitação do tamanho da base, principalmente, devido ao obstáculo do levantamento da infraestrutura de lojas existentes em períodos anteriores e até mesmo atual. Algumas sugestões de extensão da pesquisa consistem em ampliar a base de dados com uma série histórica, com variáveis dummies como crise e concessões, que podem ter impactado significativamente a receita referente ao ano de 2015 , e por fim com a abrangência de aeroportos com o mesmo perfil de movimento no Brasil e até mesmo global.

\section{REFERÊNCIAS}

ACI. (2015). 2015 ACI Airport Economics Report: Preview Edition - A comprehensive view of the industry's 2014 financial performance. Relevant statistics, Superior decision-making, Better airports. Airports Council International. Montreal, Quebéc, Canadá, 2016.

ACRP Report 25 (2010) Airport Passenger Terminal Planning and Design. Volume 1: Guidebook. Transportation Research Board. Washington, D.C., 2010.

ANAC. (2014). Relatório Financeiro dos Aeroportos da INFRAERO Ano Base 2013. Superintendência de Regulação Econômica e Acompanhamento de Mercado - SRE / Gerência de Regulação Econômica - GERE. Dezembro de 2014. 1a Edição. Brasília/DF.

Dender, K. V. (2006). Determinants of fares and operating revenues at US airports. Elsevier. Journal of Urban Economics v. 62 (2007), p. 317-336. doi: 10.1016/j.jue.2006.09.001

Del Chiappa, G.; Martin, J.C. e Roman, C. (2016). Service quality of airports' food and beverage retailers. A fuzzy approach. Elsevier. Journal of Air Transport Management v. 53 (2016), p. 105-113. doi: 10.1016/j.jairtraman.2016.02.002

DKMA. (2014). Passenger Satisfaction - The key to growing non-aeronautical revenue - Trends from the 2013 Airport Retail and F\&B Survey. DKMA. Acesso em junho de 2016, disponível em: http://www.dkma.com/en/images/downloads/commercial/Passenger\%20satisfaction\%20-\%20the\%20key\%20to\%20growing\%20non-aeronautical\%20revenue.pdf

Thomas - Emberson, S. (2007) Airport Interiors Design for Business. John Wiley \& Sons Ltd.

Fuerst, F., \& Gross, S. (2014). The Commercial Performance of Global Airports. Acesso em junho de 2016, disponível em: https://www.academia.edu/10095971/The_Commercial_Performance_of_Global_Airports?auto=download 
Gazeta do Povo. (30 de março de 2016). Gazeta do Povo. Acesso em 18 de junho de 2016, disponível em Gazeta do Povo: http://www.gazetadopovo.com.br/blogs/avioes-em-foco/infraero-registra-prejuizo-financeiro-pelo-terceiro-ano-consecutivo/

Google Maps. (2016). Acesso em 14 de Junho de 2016, disponível em https://www.google.com.br/maps/

Graham (2008) Managing Airports: An international perspective. $3^{\text {Th }}$ Edition, Elsevier Ltd.

Graham, A. (2009). How important are commercial revenues to today's airports? Elsevier, Journal of Air Transport Management 15 (2009) p. 106-111. doi:10.1016/j.jairtraman.2008.11.004

IATA (2014) Airport Development Reference Manual - ADRM. 10th Edition. Effective March 2014. ISBN 978-92-92529226-1. International Air Transport Association. Montreal - Geneva.

ICAO. (2013). Doc. 9562 - Airport Economics Manual. Third Edition. ISBN 978-92-9249-192-5. International Civil Aviation Organization. Montréal, Quebec, Canada.

ICAO. (2015). State of Airport Economics. Infrastructure Management Programme - Economic Development of Air Transport. ICAO \& ACI. 12 de Novembro de 2015. Disponível em: https://www.icao.int/sustainability/Airport_Economics/State\%20of\%20Airport\%20Economics.pdf.

Infraero. (2016). Anuário Estatístico Operacional 2015. Diretoria de Planejamento e Gestão Estratégica - DG. Superintendência de Desenvolvimento Aeroportuário - DGDR. Gerência de Estudos de Capacidade e Demanda - DRCD. Abril de 2016. Brasília/DF.

Infraero. (2016a). Contratos Comerciais - Vigentes Março/2016. Superintendência de Logística Administrativa - LABR. Gerência de Contratos e Convênios - LACC. Coordenação de Contratos de Concessão de Âreas- LACC-3.

Infraero. (2016b). Aeroportos. Acesso em 14 de Junho de 2016, disponível em http://www.infraero.gov.br/index.php/br/aeroportos.html

Jenichen, E. A. (2002). Receitas e Despesas em Aeroportos: Uma abordagem econométrica. 01 de Outubro de 2002.134 f. Dissertação (Mestrado em Transporte Aéreo e Aeroportos) - Instituto Tecnológico de Aeronáutica, São José dos Campos. 2002.

Castillo-Manzano, J. I. (2010). Determinants of commercial revenues at airports: Lessons learned from Spanish regional airports. Tourism Management 31 (6), p. 788-796, December 2010. doi:10.1016/j.tourman.2009.08.005

Ministério do Turismo. (2012). Caracterização e dimensionamento do turismo doméstico no Brasil - 2010/2011. Relatório Executivo - Produto 6 / Principais Resultados Selecionados. Fundação Instituto de Pesquisas Econômicas (FIPE). Setembro de 2012. São Paulo.

Tovar, B., \& Martín-Cejas, R. R. (2009). Are outsourcing and non-aeronautical revenues important drivers in the efficiency of Spanish airports?. Journal of Air Transport Management 15(5), p. 217-220, September 2009. doi:10.1016/j.jairtraman.2008.09.009

Volkova, N. (2009). Determinants of retail revenue for today's airports. German Airport Performance (GAP). Project Working Paper. June 2009. Berlin. 